\title{
Morphology and Economic Value of Macadamia (Macadamia integrifolia Maiden and Betche)
}

\author{
((Morfologi dan Nilai Ekonomi Makadamia (Macadamia integrifolia Maiden and Betche)) \\ Ayu Vanisa Widiastuti, Iis Nur Asyiah*), Pujiastuti \\ Program Studi Pendidikan Biologi, Fakultas Keguruan dan Ilmu Pendidikan, Universitas Jember
}

\section{ABSTRACT}

Macadamia has a scientific name Macadamia integrifolia Maiden and Betche from the Proteaceae family. The Macadamia plant habitat is in highland areas with an altitude of 1000 masl with a temperature of $\leq 32^{\circ} \mathrm{C}$. Macadamia plants are perennials with tough stems, and the branching is visible (monopodial). The purpose of this study was to determine the morphological characteristics of Macadamia plants and their economic value. The research was conducted at PTPN XII Sempol Plantation, Bondowoso with descriptive-qualitative method. The results of morphological observations showed that macadamia fruit is a dry fruit, indehiscent (when ripe the skin/shell does not break), similar to the type of achene fruit but the shell is thick and hard. Woody stems (lignosus) with monopodial branching type, incomplete leaves consisting of stalks and leaf blades, leaf blades are oblong-elongated, incised independently, pinnate leaf bones, phyllotaxis opposite crosswise. Macadamia trees can produce round fruit of about 20-70 kg per year with a monthly profit of Rp. 8,905,500. The economic potential of the Macadamia plant is very promising, as evidenced by the ongoing import of peeled macadamia with a volume of 6,862 kilograms worth US\$145,100 (approximately Rp 1.9 billion) or Rp 291,405.29 per kilogram.

Keywords: macadamia, morphologyi, economic value.

*)Corresponding author:

lis Nur Aisyah

E-mail: iisnaza.fkip@unej.ac.id

\section{PENDAHULUAN}

Makadamia (Macadamia integrifolia Maiden and Betche) merupakan tanaman pangan yang secara ekonomis sangat penting yang berasal dari Australia dengan nama lokal kacang Queensland, kacang makadamia, kacang Australia [1]. Pada tahun 2014, hasil panen makadamia di Afrika Selatan melampaui Australia, menjadikan Afrika Selatan sebagai penghasil makadamia terbesar di dunia, meskipun habitat asli tanaman tersebut adalah di Australia [2].

Makadamia telah dibudidayakan di banyak negara di dunia. Di Thailand, Makadamia telah dibudidayakan di daerah dataran tinggi selama lebih dari 40 tahun [3]. Tanaman Makadamia ini diperkenalkan di Indonesia sejak tahun 1950 sebagai tanaman koleksi di kebun raya Cibodas, lalu disebar luaskan kepada beberapa PT. Perkebunan lainnya untuk melihat perkembangan tanaman Makadamia pada beberapa tempat.
Makadamia mulai dibudidayakan secara serius pada tahun 1990 di Perkebunan Blawan, Bondowoso, Jawa Timur.

Makadamia mampu beradaptasi pada lahan dengan ketersediaan unsur hara rendah, suhu tinggi, kelembaban rendah, dan intensitas cahaya tinggi. Pohon ini juga tidak memerlukan perawatan intensif, tidak banyak gugur daun, tahan kebakaran dan mudah bertunas kembali setelah terbakar. Pohon ini tumbuh di sekitar bebatuan serta mampu mengikat air, yang dicerminkan dari kondisi kelembaban tanah yang lebih tinggi. Batang memiliki kulit beralur dan tebal dengan percabangan yang banyak. Jika batang patah atau terpotong maka akan muncul tunas (trubusan) baru, tajuk lebar dan padat sehingga menghambat masuknya cahaya serta mengurangi curah hujan yang jatuh [4].

Habitat tanaman Makadamia cocok pada daerah dengan ketinggan lebih dari $1000 \mathrm{~m}$ diatas permukaan laut dan suhu optimum $\leq 32^{\circ} \mathrm{C}[5]$. Di Indonesia, 
makadamia tumbuh baik di dataran tinggi Ijen Bondowoso, Cibodas Cianjur, dan Lembang Bandung yang merupakan kawasan dataran tinggi, dengan elevasi lebih dari $1000 \mathrm{~m}$ diatas permukaan laut (dpl). Namun demikian, makadamia yang tumbuh di dataran tinggi Ijen paling produktif dengan kualitas buah paling baik. Biasanya tanaman ini menjadi tanaman penaung pada lahan perkebunan kopi, hal ini dikarenakan daunnya yang lebat.

Pada umumnya orang mengenal hanya sebatas kacang tanah, kacang mete atau kacang almond. Namun ketika mendengar nama kacang makadamia, sebagian orang belum mengenalnya, padahal selain rasanya lebih enak juga harganya jauh lebih mahal, bahkan dikenal sebagai kacang termahal. Tujuan penelitian ini adalah untuk mengetahui morfologi dan nilai ekonomi makadamia.

\section{METODE PENELITIAN}

Metode penelitian yang digunakan adalah metode deskriptif-kualitatif. Kegiatan penelitian ini meliputi pengumpulan data melalui pengamatan langsung maupun wawancara, analisis data, interprestasi data, dan merumuskan kesimpulan.

\section{Tempat dan Waktu Penelitian}

Penelitian dilaksanakan di PT. Perkebunan Nusantara XII Desa Sempol Kecamatan Jampit Kabupaten Bondowoso. Tahap observasi dilakukan bulan Juli 2019. Tahap pengambilan sampel dan pengambilan gambar atau dokumentasi yang dilakukan pada Februari 2020.

\section{Alat dan Bahan Penelitian}

Alat yang digunakan dalam penelitian ini adalah berupa buku catatan, kamera, dan alat tulis. Alat yang digunakan untuk membuat herbarium adalah, kertas koran, kertas karton, mika, selotip, baskom/ semprotan.

Bahan yang digunakan dalam penelitian ini adalah berupa tanaman makadamia dan alkohol $70 \%$ untuk mengawetkan tanaman mencegah tumbuhnya bakteri dan jamur.

\section{Identifikasi Tanaman, Dokumentasi, dan Analisis Data \\ Identifikasi tanaman secara langsung dengan}

melakukan pengamatan morfologi tanaman meliputi daun, bunga, buah, dan batang kemudian dicocokan dengan pustaka, selanjutnya bagian tanaman tersebut dijadikan bahan untuk membuat herbarium.

Proses dokumentasi dilakukan saat observasi dan pengambilan sampel, dokumentasi berupa foto dan video. Analisis nilai ekonomi macadamia dilakukan berdasarkan hasil wawancara.

\section{HASIL DAN PEMBAHASAN}

\section{Identifikasi Morfologi Tanaman Makadamia (M. integrifolia)}

Tanaman Makadamia merupakan tanaman tahunan dengan batang yang keras, tipe percabangan monopodial, ketinggian tanaman bisa mencapai $20 \mathrm{~m}$ (Gambar 1).

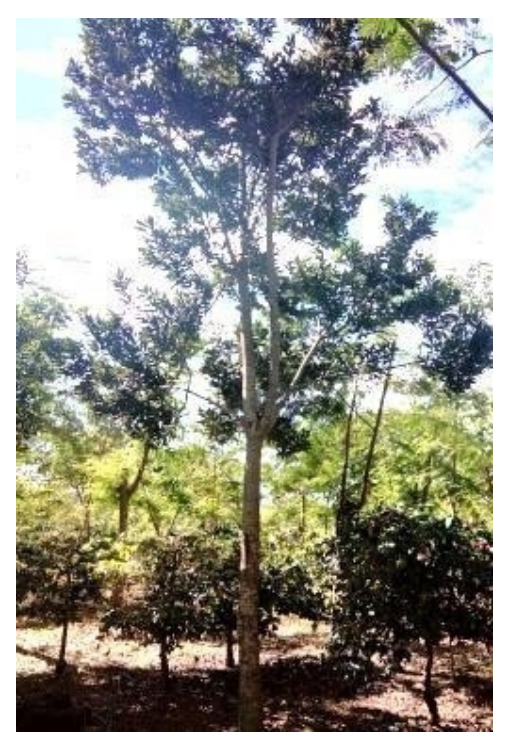

Gambar 1. Habitus Tanaman Makadamia (Macadamia integrifolia) (Koleksi Pribadi)

\section{Akar}

Tanaman Makadamia memiliki sistem perakaran tunggang, dan termasuk kedalam jenis akar tunggang yang tidak bercabang atau sedikit bercabang. Akar tunggang yang tidak bercabang atau sedikit cabang memiliki bentuk yang bermacam-macam, yaitu berbentuk sebagai tombak, berbentuk gasing, dan berbentuk benang. Tanaman Makadamia termasuk dalam bentuk akar tunggang berbentuk benang, karena akar tunggangnya kecil panjang seperti akar serabut dan sedikit sekali bercabang (Gambar 2). 


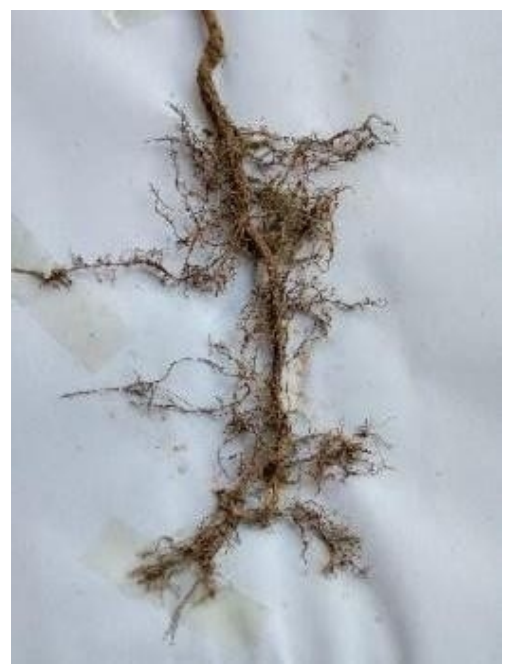

Gambar 2. Akar Bibit Makadamia Integrifolia) (Koleksi Pribadi)

(Macadamia

\section{Batang}

Makadamia (Macadamia integrifolia) merupakan tanaman tahunan dengan batang yang keras berkayu (lignosus). Tanaman Makadamia, memiliki batang yang pada bagian bawahnya lebih besar dan ke ujung semakin mengecil. Permukaan dari batang tanaman Makadamia ini beralur (sulcatus) yaitu terdapat alur-alur yang jelas pada arah membujur, serta memiliki arah tumbuh batang yang tegak lurus yaitu arah tumbuhnya adalah tegak lurus ke atas. Percabangan pada tanaman Makadamia termasuk pada percabangan monopodial yaitu batang pokok selalu tampak jelas karena lebih besar dan Panjang dibanding cabang-cabang pohon (Gambar 3).

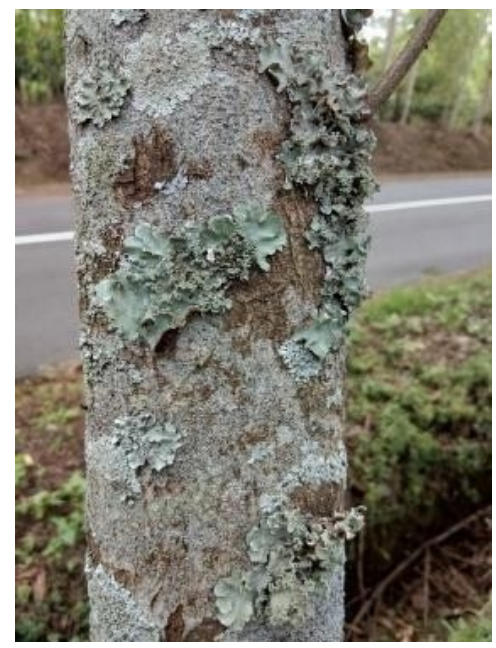

Gambar 3. Batang Makadamia (Macadamia integrifolia) (Koleksi Pribadi)
Tanaman Makadamia, memiliki tipe arah cabang condong keatas karena cabangnya membentuk sudut $45^{\circ}$ dari batang pokok. Pangkal pada batang merupakan alat bagi tumbuhan untuk mempertahankan kehidupan tumbuhan itu sendiri pada masa buruk. Tanaman Makadamia termasuk pada tumbuhan menahun/tumbuhan keras karena tanaman ini dapat mencapai usia tanaman bertahuntahun, hal ini dapat dibuktikan bahwa untuk perkembangan tanaman Makadamia perlu waktu 7 - 8 tahun untuk menghasilkan buah Makadamia yang siap untuk dipanen [6].

\section{Daun}

Daun yang memiliki bagian upih daun (vagina), tangkai daun (petiola) dan helaian daun (lamina) disebut daun lengkap. Daun yang tidak memiliki salah satu bagian daun disebut daun tidak lengkap, misalnya daun yang hanya memiliki tangkai dan helaian daun saja. Tanaman Makadamia ( $M$. integrifolia) termasuk kedalam jenis tanaman yang memiliki daun tidak lengkap karena terdiri dari tangkai dan helaian daun saja, disebut juga dengan daun bertangkai (Gambar 4 a).

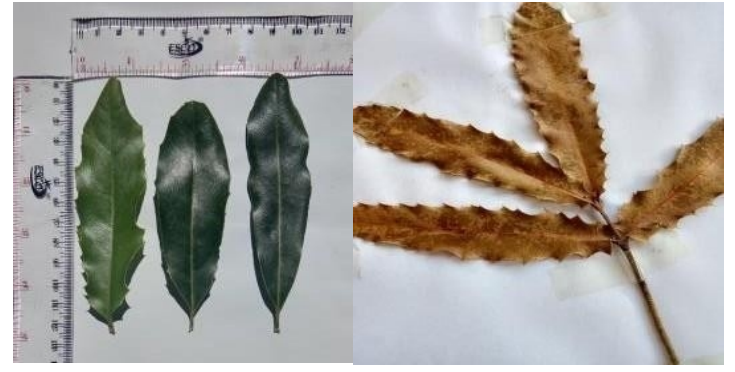

a

b

Gambar 4. a) Morfologi Daun Makadamia (Macadamia integrifolia); b) Filotaksis Daun Makadamia (Macadamia integrifolia) (KoleksiPribadi)

Helaian daun Makadamia termasuk pada helaian daun berbentuk jorong memanjang, karena bentuknya diantara memanjang dan bangun lanset. Daun Makadamia (M. integrifolia) memiliki tipe tulang daun menyirip, karena memiliki satu ibu tulang dari pangkal menuju ujung daun dan merupakan terusan dari tangkai daun., sedangkan tulang daun sekunder merupakan cabang tulang daun primer, tersusun ke arah kiri dan kanan tulang daun primer. Daun makadamia (M. integrifolia) memiliki daun yang bertoreh merdeka, yaitu toreh yang tidak 
mempengaruhi bentuk asli daun. Jenis dari daun bertoreh merdeka yang ada dalam daun tanaman Makadamia adalah bergigi, karena sinus pada bagian daunnya lebih tumpul dibandingkan angulusnya. Daun Makadamia, dalam perkembangannya mengalami perubahan pada bagian tepinya. Pada saat muda, daun memiliki tepi yg bertoreh, kemudian berangsur angsur berkurang kedalaman torehnya, sehingga Ketika daun sudah dewasa, menjadi tidak bertoreh.

Tata letak daun makadamia berhadapan- bersilang, karena dua daun pada setiap buku letaknya berhadapan dan terpisah dengan jarak $180^{\circ}$ dan bersilang dengan daun dibawahnya (Gambar 4 b).

\section{Bunga}

Bunga makadamia ( $M$. integrifolia) merupakan bunga yang termasuk kedalam golongan bunga majemuk tak terbatas, karena pada bagian ujung ibu tangkai perbungaan tidak terdapat bunga, jadi ibu tangkainya dapat tumbuh terus menerus sampai sesuai ukuran maksimalnya. Secara keseluruhan, susunan perbungaan pada Makadamia ini adalah bulir majemuk. Ibu tangkai bunga bercabang cabang, dan setiap cabangnyanya merupakan rangkaian bunga yang tersusun dalam bulir jadi bunganya terletak tidak langsung pada ibu tangkai.

Bunga Makadamia termasuk kedalam bunga yang tidak lengkap, karena perhiasan bunganya tidak memiliki kelopak (calyx). Penyusun bunga terdiri dari bagian bagian; tangkai bunga (pedicellus), mahkota bunga (petal) dan bagian alat kelamin bunga. Kelamin betina merupakan putik yg terdiri dari kepala putik (stigma), bakal buah (ovary), saluran menuju ovary (style); sedangkan kelamin jantan berupa benangsari (stamen), yang terdiri dari tangkai sari (filamen) dan kepala sari (anther) yang berisi serbuk sari didalamnya. Menurut letak dari alat kelamin jantan dan betina, bunga Makadamia termasuk dalam tanaman berumah satu yaitu alat kelamin bunga Makadamia terdapat di bunga yang sama dalam satu tangkai.

Bunga Makadamia (M. integrifolia), tidak memiliki kelopak bunga dan seringkali disebut dengan bunga tanpa kelopak. Bunga pada Makadamia memiliki bagian yang disebut dengan petal yaitu keseluruhan bagian dari mahkota bunga yang berukuran $1 \mathrm{~cm}$. Menurut (5) kepala sari pada bunga Makadamia menghasilkan serbuk sari/pollen yang berbentuk tetrahedral, pollen merupakan bagian bunga yang berupa kantung berisi gametofit jantan pada tumbuhan berbunga Anthophyta baik Gymnospermae dan Angiospermae. Pollen/serbuk sari Makadamia memiliki ukuran sekitar $0,29 \mathrm{~mm}$. jika berkecambah, serbuk sari ini akan berperan untuk membuahi sel telur di dalam bakal biji/ovule.

Putik/alat kelamin betina pada bunga, khususnya pada bagian bakal buah/ovarium, mengandung bakal biji/ovule yang memiliki sel telur/ovum. Sel telur yang setelah dibuahi oleh sel sperma yang ada dalam serbuk sari,akan berkembang menjadi embryo, dan bakal biji akan berkembang menjadi biji, sedangkan bakal buah akan berkembang menjadi buah. (Gambar 5).

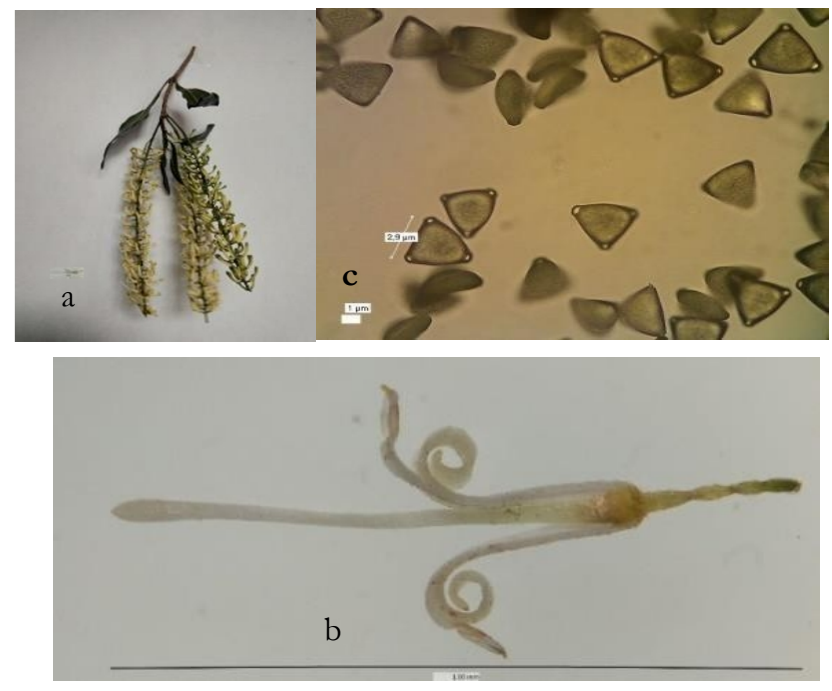

Gambar 5. Morfologi Bunga Makadamia (Macadamiaintegrifolia): a) Letak bunga Makadamia pada tangkai; b) Bagian benangsari bunga Makadamia dengan perbesaran 10x0,67 kali; c) Bentuk pollen bunga Makadamia dengan perbesaran 40x10 kali (Koleksi Pribadi) 
Makadamia bersifat protandrous yaitu butiran serbuk sari sudah matang dan cenderung menyebar sebelum stigma menjadi reseptif. Ovarium unicarpelar mengandung dua ovula, tetapi hanya satu yang berkembang menjadi biji [6].

\section{Buah dan Biji}

Buah Makadamia berasal dari bakal buah, dalam satu buah terdiri dari satu biji, dan dinding buahnya tebal berdaging. Dinding buah terdiri tiga lapisan yaitu kulit luar (epicarpium), kulit tengah (mesocarpium), dan kulit dalam (endocarpium), sehingga buah macadamia termasuk buah sejati tunggal berdaging tipe drupe (Gambar 6 dan 7).

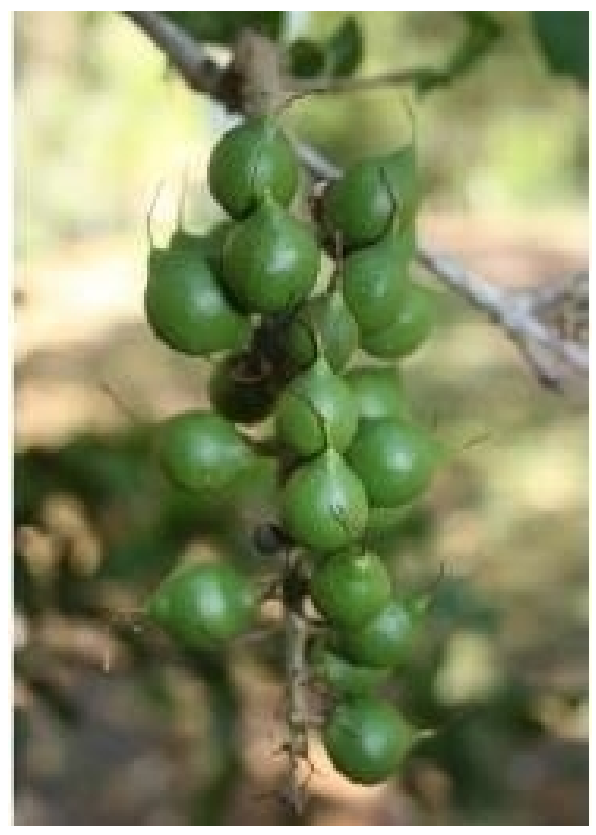

Gambar 6. Buah Makadamia (Macadamia integrifolia) (Koleksi Pribadi)

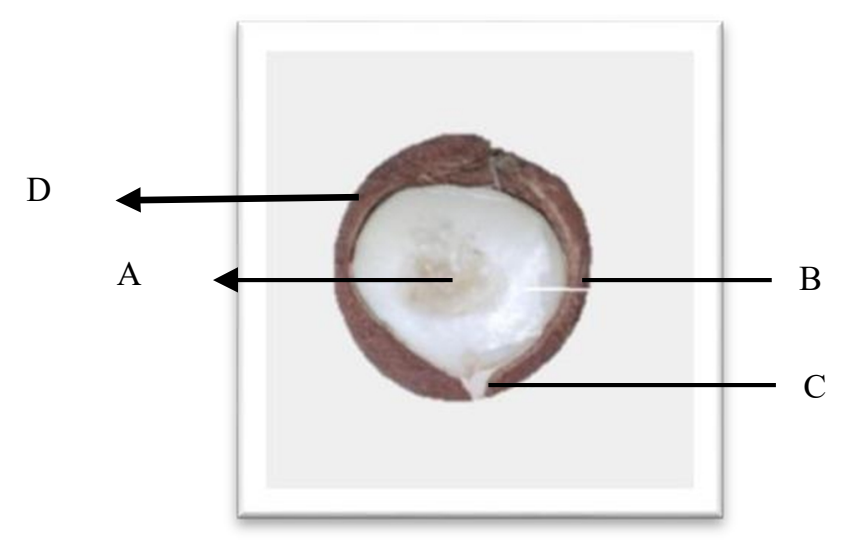

Gambar 7. Morfologi Biji Makadamia (Macadamia integrifolia) (Kusuma, 2018)
Biji makadamia ( $M$. integrifolia) terdiri dari beberapa bagian yaitu kulit biji (spermodermis), tali pusar (funiculus), dan inti biji (nucleus). Makadamia termasuk dalam tanaman biji belah (Dicotyledoneae) yaitu tanaman yang bijinya memiliki lembaga dengan dua daun lembaga. Tipe perkecambahan biji macadamia termasuk epigeal yaitu pembentangan ruas batang dibawah daun lembaga terangkat keatas tanah. Kulit dalam/ bagian lunak dari kulit makadamia sangat tipis, selanjutnya kulit luarnya, berupa tempurung yang sangat keras, meskipun tebalnya hanya sekitar $1 \mathrm{~mm}$. Di dalam tempurung terdapat endosperm makadamia berbentuk bulat, berdiameter $3 \mathrm{~cm}$ berwarna putih kekuningan, lunak dan rasanya gurih (Gambar 7).

Biji makadami mengandung asam olieat, asam palmitoleat dan senyawa polifenol yang bermanfaat bagi kesehatan. Komponen bermanfaat lain dari Makadamia adalah kandungan mikronutrien esensial seperti kalium, magnesium, kalsium, dan fosfor. Makadamia juga mengandung vitamin B kompleks e niachin, thiamin, riboflavin, vitamin $\mathrm{C}$ [5].

\section{Potensi Ekonomi Makadamia}

Badan Pusat Statistik (BPS) mencatat tahun 2017 Indonesia mengekspor makadamia gelondong/ berkulit dan kupas $260 \mathrm{~kg}$ senilai US\$2.578. Pada saat Kurs Rp 13.781 per dollar AS, nilainya Rp 35,5 juta atau Rp 136.648 per kg. Tetapi pada tahun 2017, Indonesia juga mengimpor makadamia kupas dengan volume 6.862 kilogram senilai US $\$ 145.100$ (sekitar Rp 1,9 miliar) atau per kg Rp 291.405,29 (Rahardi,F. 2018).

Pohon Makadamia mampu menghasilkan buah glondong sekitar 20-70 kg per tahunnya, namun buah Makadamia dalam bentuk glondong perlu disortir kembali sebelum dipasarkan menjadi dalam bentuk cangkang dan nut. Setiap $1 \mathrm{Ha}$ lahan Makadamia terdiri dari sekitar 180 pohon memerlukan sekitar 20 orang pekerja untuk melakukan perawatan sampai proses panen dilakukan.

Dalam menghasilkan produksi Makadamia yang baik dan memenuhi standar, petani/perusahaan memerlukan biaya operasional berupa biaya variabel dengan biaya tetap setiap bulannya. Biaya operasional dapat dilihat dalam Tabel 1 dan 2.

Berdasarkan Tabel 5 dan 6, total biaya operasional sebesar Rp. 45.392.375 dan pendapatan per panen 
sebesar Rp.141.950.000, sehingga keuntungan per tahun sebesar Rp.96.557.625, dan keuntungan per bulan yang bisa diperoleh petani/ perusahaan sebesar Rp.8.905.500.

Tabel 1. Biaya Tetap

\begin{tabular}{cll}
\hline No & Biaya & Nilai $(1 / 5$ dari total $)$ \\
\hline 1. & Penyusutan Kesrik Piringan Pohon Rp.3.450.000 & Rp. 690.000 \\
2. & Penyusutan PembersihanLahan Rp. 8.587.500 & Rp. 1.717 .500 \\
3. & Penyusutan Tanam Makadamia Rp.1.437.500 & Rp. 287.500 \\
4. & Penyusutan Wiwil Cabang Rp. 5.550.000 & Rp. 1.110 .000 \\
5. & Penyusutan penyiangan kimiawi Rp. 1.449.500 & Rp. 289.900 \\
6. & Penyusutan penyiangan manual Rp. 9.300.000 & Rp. 1.860 .000 \\
7. & Upah Mandor (Rp.1.094.632@14 orang) & Rp.78.188 \\
\hline Total Biaya Tetap & Rp.6.033.088 \\
\hline
\end{tabular}

Tabel 2. Biaya Variabel

\begin{tabular}{cll}
\hline No & Biaya & Nilai (1/6 dari total) \\
\hline 1. & TSP 36 Rp.53.099.070 & Rp.8.849.845 \\
2. & UREA Rp.109.882.250 & Rp.18.313.708 \\
3. & KCl Rp. 73.174.406 & Rp.12.195.734
\end{tabular}

\section{KESIMPULAN}

Tanaman Makadamia memiliki nama ilmiah ( $M$. integrifolia) dari famili Proteaceae, habitat tanaman Makadamia ini pada daerah dataran tinggi dengan ketinggian $1000 \mathrm{mdpl}$ dengan suhu $\leq 32^{\circ} \mathrm{C}$. Batang makadamia berkayu (lignosus) dengan tipe percabangan monopodial, daun tidak lengkap terdiri dari tangkai dan helaian daun, helaian daun berbentuk jorongmemanjang, bertoreh merdeka pada saat muda dan menjadi tidak bertoreh pada saat daun telah dewasa, tulang daun menyirip, filotaksis berhadapan bersilang. Bunga makadamia merupakan bunga majemuk tak terbatas, dengan tipe buah kering, indehiscent (saat matang kulit/cangkang tidak pecah), mirip dengan tipe buah achene namun cangkangnya tebal dan mengeras.

Potensi ekonomi yang dimiliki tanaman Makadamia sangat menjanjikan sehingga bisa dikembangkan pada berbagai wilayah Indonesia dengan lingkungannya cocok untuk tanaman Makadamia yang selanjutnya bisa menambah devisa negara.

\section{UCAPAN TERIMA KASIH}

Penulis mengucapkan terima kasih kepada PT. Perkebunan Nusantara XII yang telah memberikan izin untuk melakukan penelitian mengenai tanaman Makadamia di Perkebunan Sempol, Jampit Kabupaten Bondowoso, Jawa Timur.

\section{DAFTAR PUSTAKA}

[1] S. Ryan, Conservation Management Profile: Queensland Nut Tree Macadamia integrifolia. Ecosystem Conservation Branch, EPA, 2006.

[2] I. Grass, M. Svenja, J. T. Peter. Taylor, F Stefan, H. Peter. and T. Teja. "Pollination Limitation Despite Managed Honeybees in South African makadamia orchards". Agriculture, Ecosystems, and Environment, vol. 260, no. 2, pp.12-18, June 2018.

[3] C. Borompichaichartkul, N. Chinprahast, S. Devahastin, L. Wiset, N. Poomsa-ad, and T. Ratchapo. Multistage Heat Pump Drying of Macadamia nut Under Modified Atmosphere. International Food Research Journal, vol. 20, no. 5, pp 2199-203, April 2013.

[4] Aswandi. Pratiara, dan R.K. Cut. Pengembangan Agroforestry Makadamia dan Lebah Madu: Upaya Rehabilitasi Lahan Kritis di Danau Toba. Policy Brief, Vd 11, no. 11, pp: 3-5, 2017. 
[5] L.G. Wood and L.G. Manohar. Macadamia Nuts (Macadamia integrifolia and tetraphylla) and Their Use in Hypercholesterolemic Subject. In Nuts and Seeds in Health and Disease Prevention, Victor R. Preedy, R.W. Ronald, and B.P. Vinood, Eds. Elsevier Inc, 2011, pp 717-725.

[6] Direktorat Jenderal Perkebunan, Departemen Pertanian. Pedoman Budidaya Makademia (Macadamia integrifolia). 2006, pp 36. 